\title{
Estimated health and economic impact of quadrivalent HPV (types 6/11/16/18) vaccination in Brazil using a transmission dynamic model
}

\author{
Kosuke Kawai ${ }^{i^{*}}$, Gabriela Tannus Branco de Araujo ${ }^{2}$, Marcelo Fonseca ${ }^{2,3}$, Matthew Pillsbury ${ }^{4}$ and Puneet K Singhal ${ }^{5}$
}

\begin{abstract}
Background: Cervical cancer is the second most common cancer among women in Brazil. We examined the health and economic impacts of quadrivalent HPV vaccination in Brazil.

Methods: We adapted a previously developed transmission dynamic model to estimate the effectiveness of HPV vaccination on cervical cancer, cervical intraepithelial neoplasia grades 2 and 3 (CIN2/3), CIN1, and genital warts. We evaluated following vaccination strategies: routine vaccination of 12 -year-old girls and routine vaccination in combination with a catch-up vaccination of 12 to 26 -year-old women.

Results: The model projected that the vaccination would reduce the incidence rates of HPV 6/11/16/18-related cervical cancer, CIN2/3, CIN1, and female genital warts by $94 \%$ to $98 \%$ at year 100 . Routine vaccination in combination with a catch-up vaccination could prevent approximately 163,000 cases of cervical cancer, 48,000 deaths from cervical cancer, 2.3 million cases of CIN2/3, and 11.4 million genital warts in the next 50 years. The incremental cost-effectiveness ratios for female vaccination strategies ranged from $\mathrm{R} \$ 350$ to $\mathrm{R} \$ 720$ (US\$219 to US\$450) per quality-adjusted life year (QALY) gained.
\end{abstract}

Conclusions: Our study demonstrates that quadrivalent HPV female vaccination can be a cost-effective public health intervention that can substantially reduce the burden of cervical diseases and genital warts in Brazil.

\section{Background}

Every year, nearly 530,000 women develop cervical cancer and 275,000 die from the disease worldwide [1]. About $88 \%$ of deaths from cervical cancer occur in developing countries [1]. Human papillomavirus (HPV) is the primary cause of cervical cancer, with HPV-types 16 and 18 causing approximately $70 \%$ of cases globally [2]. A quadrivalent HPV vaccine against HPV-types 6, 11,16 , and 18 (Gardasil $^{\circledR}$ by Merck \& Co., Inc.) was recently developed and is widely available around the world [3-5].

Cervical cancer is the second most common cancer among women in Brazil. The cervical cancer incidence rate is two to three times higher in Brazil (19.2 per 100,000 women every year) than in North America and Europe [6]. The quadrivalent HPV vaccine was approved for use in Brazil to prevent cervical, vulvar, and vaginal

\footnotetext{
* Correspondence: kkawai8@gmail.com

${ }^{1}$ Temple University, 3307 N. Broad Street, Philadelphia, PA, 19140, USA

Full list of author information is available at the end of the article
}

cancer, precancerous lesions, and genital warts caused by HPV types $6,11,16$, and 18 . However, HPV vaccination has not been introduced as a national program in Brazil. Understanding the health and economic impacts of HPV vaccination is essential for policy makers to make decisions regarding the introduction of national vaccination programs. Previous cost-effectiveness studies of HPV vaccination in Brazil and other middle-income countries have used a range of different methods [7-11]. Because the mathematical transmission dynamic model is required to describe the transmission of HPV infections and diseases, we used this method to examine the effectiveness of HPV vaccination.

The purpose of our study was to examine the longterm health and economic impacts of quadrivalent HPV vaccination in Brazil using a transmission dynamic model. We evaluated the following vaccination strategies: routine vaccination of 12-year-old girls and routine vaccination of 12 -year-old girls in combined with a catch-up vaccination of 12 to 26-year-old women. 


\section{Methods}

We adapted a previously developed transmission dynamic model to evaluate the health and economic impacts of HPV vaccination in Brazil [12]. The transmission dynamic model incorporates the direct and indirect benefits (herd immunity) of vaccination. Details of the model have been previously published [12-14]. Here, we briefly described the model structure and methods for adapting the model to Brazil.

\section{Model structure}

The model has demographic and epidemiologic components. The population is divided into sex and 23 age groups to simulate demographic characteristics of the population. Individuals die at sex- and age-specific rates within each group, and individuals are born into the youngest age group at a rate that balances mortality. Each group is further stratified into three sexual activity groups (low, medium, and high rates of sexual partner change). The model accommodates general patterns of mixing between age and sexual activity group. The epidemiologic component of the model simulates heterosexual transmission of HPV-types 6/11/16/18 and progression to cervical intraepithelial neoplasia (CIN) grades 1,2, and 3, cervical cancer, and genital warts. The population is divided into epidemiologic compartments according to the host's susceptibility to infection or the host's status with respect to infection, immunity, disease, screening, and treatment. All model simulations were conducted in Mathematica ${ }^{\circledR}$ (Wolfram Research, Champaign, IL, USA).

\section{Model parameters}

Model parameters regarding the natural history of HPV $6 / 11 / 16 / 18$ infections and diseases, as well as diagnostic characteristics were based on a previous literature review [12]. Assuming that the natural history parameters are similar, we kept the same parameter values used in the U.S. model for Brazil. For model parameters for demographics, sexual behaviors, and clinical management of HPV-related diseases, we conducted a comprehensive literature review to obtain data for Brazil (Table 1) [15-21]. The information collected for clinical management of HPV-related diseases were age-specific cervical cytologic screening and hysterectomy rates and age and stage-specific cervical cancer mortality rates. When data from Brazil were not available, we used data from another country from the same region of the world. Based on the recent literatures, we assumed that approximately $70 \%$ of targeted women would receive regular cervical cytologic screening with specific annual screening rates by age (Table 1). We also assumed that that the current screening practice would remain the same throughout the 100 year time horizon.

\section{Vaccine strategies and characteristics}

We examined the health and economic impacts of three different scenarios: 1) no vaccination, 2) routine vaccination of 12-year-old females, and 3) routine vaccination of 12-year-old females with a catch-up vaccination of 12 to 26 -year-old females. Assuming that the national vaccination program will be school-based, routine vaccination coverage was assumed to gradually cover $85 \%$ of girls by 12 years of age. We assumed that a catch-up program among women 12 to 26 years of age would gradually increase to cover $95 \%$ by 26 years of age. All vaccinated women were assumed to complete a three-dose regimen. We assumed the duration of vaccine protection to be lifelong. We also examined a 20-year duration of protection in a sensitivity analysis. We estimated the cost of vaccination using the Pan American Health Organization (PAHO) vaccine acquisition cost per dose in 2011 (US\$15.15 per dose). We assumed a total cost of the three vaccine series to be $\mathrm{R} \$ 72.72$ (US\$45.45). The model incorporates the vaccine efficacy from the most recent clinical trials [12].

\section{Economic data and health utility parameters}

Costs were estimated from the perspective of the healthcare system in Brazil. The costs of cytology screening and diagnosis were based on the official value reimbursed by the public health care in Brazil (Table 2) [22]. The costs associated with treatment of genital wart, $\mathrm{CIN}$, and cervical cancer cases are based on published data [7,22]. Quality-adjusted life years (QALYs) were estimated based on health utilities. Because the health utility data were not available from Brazil, we used the same health utility values from the U.S. [12]. Total QALYs were estimated by weighting survival time by the quality of life weights associated with each health state. We examined the cost-effectiveness of introducing HPV vaccination over a time horizon of 100 years. Costs and QALYs were discounted at $3 \%$.

\section{Model simulations and validation}

Model validation of the natural history component of the U.S. model has been described previously. We assessed the predictive validity of the model by comparing the model outputs and observed epidemiological data regarding cervical cancer incidence and mortality. Age-standardized incidence rate of cervical cancer was 19.2 per 100,000 women per year and cervical cancer mortality rate was 7.3 per 100,000 women per year in Brazil $[6,23]$. Assuming that $70.7 \%$ of cervical cancer is attributable to HPV-types 16 and 18, the HPV16/18related cervical cancer rate is estimated to be 13.6 per 100,000 women per year and the HPV16/18-related cervical cancer mortality rate is estimated to be 5.2 per 100,000 per year [24]. The model projected an incidence 
Table 1 Demographic, sexual behavior, cervical cancer screening, and disease model parameters

\begin{tabular}{lccc}
\hline Parameter & Estimate & & Source \\
\hline $\begin{array}{l}\text { Demographic variables } \\
\text { Total population size }\end{array}$ & $203,429,773$ & & {$[15]$} \\
$\begin{array}{l}\text { Annual all-cause mortality rate } \\
\text { by sex and age }\end{array}$ & (Data not shown) & & {$[16]$} \\
$\begin{array}{l}\text { Sexual behavior variables } \\
\text { Annual mean number of sexual }\end{array}$ & Male & Female & {$[17]$} \\
partners by sex & & & \\
15-19 yrs & 1.65 & 1.29 & \\
$20-24$ yrs & 1.89 & 1.07 & \\
$25-34$ yrs & 1.40 & 1.06 & \\
35-44 yrs & 1.22 & 0.98 & \\
45-59 yrs & 1.15 & 0.79 & \\
Screening variables & & &
\end{tabular}

Screening variables

Cervical cancer screening rate,

$\%$ past 3 years

Female

70

[18-20]

Cervical cancer screening rate,

$\%$ past year

$\begin{array}{ll}<20 \text { yrs } & 0.0 \\ 20-29 \text { yrs } & 26.0 \\ 30-34 \text { yrs } & 30.3 \\ 35-39 \text { yrs } & 32.6 \\ 40-44 \text { yrs } & 30.8 \\ 45-49 \text { yrs } & 30.0 \\ 50-54 \text { yrs } & 28.6 \\ 55-69 \text { yrs } & 26.4 \\ >70 \text { yrs } & 10.0\end{array}$

Disease variables

Cervical cancer mortality rates, per year

Localized cervical cancer

$\begin{array}{ll}<40 \text { yrs } & 0.135 \\ 40-49 \text { yrs } & 0.066 \\ 50-59 \text { yrs } & 0.090 \\ 60-69 \text { yrs } & 0.100 \\ >70 \text { yrs } & 0.130\end{array}$

Regional cervical cancer

$\begin{array}{ll}<40 \text { yrs } & 0.202 \\ 40-49 \text { yrs } & 0.100 \\ 50-59 \text { yrs } & 0.136 \\ 60-69 \text { yrs } & 0.150 \\ >70 \text { yrs } & 0.195\end{array}$

Distant cervical cancer

$\begin{array}{ll}<40 \text { yrs } & 0.808 \\ 40-49 \text { yrs } & 0.399 \\ 50-59 \text { yrs } & 0.543\end{array}$

Table 1 Demographic, sexual behavior, cervical cancer screening, and disease model parameters (Continued)

\begin{tabular}{ll}
\hline $60-69$ yrs & 0.602 \\
$>70$ yrs & 0.780
\end{tabular}

Population level hysterectomy rates, \% per year

$\begin{array}{ll}<25 \text { yrs } & 0.01 \\ 25-29 \text { yrs } & 0.03 \\ 30-34 \text { yrs } & 0.12 \\ 35-39 \text { yrs } & 0.36 \\ 40-44 \text { yrs } & 0.67 \\ 45-54 \text { yrs } & 0.58 \\ 55-69 \text { yrs } & 0.20 \\ >70 \text { yrs } & 0.20\end{array}$

of HPV16/18-related cervical cancer of 13.5 per 100,000 women per year and HPV16/18-related cancer mortality of 5.0 per 100,000 per year. Data regarding the incidence rates of genital warts and CIN were limited [25-27]. The model projected overall incidence of HPV6/11-related genital warts to be 165 per 100,000 per year. The observed overall incidence of genital warts reported in other parts of the world ranged from 100 to 200 episodes per 100,000 per year, with approximately $90 \%$ of cases attributable to HPV6/11 [28-30].

\section{Sensitivity analysis}

The previous analysis in the U.S model has identified the most influential parameters [12]. Based on the previous findings, we conducted a one-way sensitivity analysis on parameters that incorporates different values for duration of vaccine protection, costs of vaccine series, [21] vaccine coverage rates, HPV-related disease cost, and discounting. We also examined a scenario assuming no quality of life adjustments. In addition, we examined a

Table 2 Cost of diagnosis and treatment of HPV-related diseases

\begin{tabular}{lccc}
\hline Parameter & R\$ & US\$ & References \\
\hline Genital warts-Female & 94 & 59 & {$[22]$} \\
Genital warts-Male & 114 & 71 & {$[22]$} \\
Cervical cancer screening and visit & 17 & 11 & {$[22]$} \\
Colposcopy & 3 & 2 & {$[22]$} \\
Biopsy & 24 & 15 & {$[22]$} \\
CIN1 episode-of-care & 175 & 109 & {$[22]$} \\
CIN2 episode-of-care & 534 & 334 & {$[22]$} \\
CIN3 episode of care & 534 & 334 & {$[22]$} \\
Localized cervical cancer & 7769 & 4856 & {$[7]$} \\
Regional cervical cancer & 6520 & 4075 & {$[7]$} \\
Distant cervical cancer & 6520 & 4075 & {$[7]$} \\
\hline
\end{tabular}


scenario assuming no effect of HPV-types 6 and 11. Finally, we examined a pessimistic scenario that assumed 20 years of vaccine protection, low HPV-related disease cost (decreased by 25\%), and high health utility values (0.97 for HPV-related disease).

\section{Results}

\section{Health impact of HPV vaccination}

The model projected that routine quadrivalent HPV vaccination of 12-year-old girls will reduce the incidence rate of HPV16/18-related cervical cancer by $59 \%$ at year 50 and by $97 \%$ at year 100 (Figure 1). The HPV16/18related cervical cancer mortality rate was also projected to decline by $97 \%$ at year 100 . The routine vaccination of 12-year-old girls in combination with a catch-up vaccination of 12 to 26-year-old women will achieve greater and earlier reduction in the number of cumulative cases and deaths from cervical cancer than the routine vaccination. Routine vaccination in combination with a catch-up vaccination will reduce the incidence rate of HPV16/18-related cervical cancer by $71 \%$ at year 50 and by $99 \%$ at year 100 . We estimated that routine vaccination in combination with a catch-up vaccination could prevent 162,769 cumulative cases of cervical cancer by year 50 and 795,693 cases by year 100 (Table 3). Routine vaccination in combination with a catch-up vaccination could prevent 47,802 cumulative deaths from cervical cancer by year 50 and 278,283 deaths by year 100 .

Our model projected that the HPV vaccination program will reduce the incidence rates of genital warts among women and men, and CIN2/3 before it reduces the incidence rate of cervical cancer (Figure 1). The model projected that routine vaccination of 12-year-old girls will reduce the incidence of HPV6/11-related genital warts among females by $94 \%$, HPV6/11/16/18-related CIN1 by $98 \%$, and HPV16/18-related CIN2/3 by $98 \%$ at year 100. Through reducing HPV6/11 infections, routine female vaccination could also provide indirect benefits to men by reducing the incidence of genital warts by $70 \%$ at year 100. Compared to routine vaccination, routine vaccination in combination with a catch-up vaccination could result in earlier and greater reduction in the cumulative cases of genital warts, CIN1, and CIN2/3 (Table 3). Routine vaccination in combination with a catch-up vaccination could avoid 508,433 cumulative cases of genital warts among women and men in the first 10 years and 3,872,287 cumulative cases in the first 25 years.

\section{Economic impact of HPV vaccination}

Routine vaccination program could avoid a total cost of approximately $\mathrm{R} \$ 1.74$ billion (US\$1.09 billion) from HPV6/11/16/18-related diseases in the next 100 years, while routine vaccination in combination with a catch- up vaccination program could avoid $\mathrm{R} \$ 2.10$ billion (US\$1.31 billion) in the next 100 years (discounted at $3 \%$ ). We estimated that about $67.3 \%$ of the total avoided costs from routine and a catch-up vaccination program would be from cervical diseases and $32.7 \%$ would be from genital warts.

The incremental cost-effectiveness ratio (ICER) for routine vaccination of 12-year-old girls' strategy compared to no vaccination strategy was R $\$ 350$ per QALY gained (US\$219 per QALY gained; Table 4). Routine vaccination in combination with a catch-up vaccination of 12 to 26-year-old women was a more effective strategy than the routine vaccination, with an ICER of $\mathrm{R} \$ 720$ per QALY gained (US\$450 per QALY gained).

We also conducted sensitivity analyses (Table 5). Assuming no quality of life benefits, the ICER for routine vaccination was R\$404 (US\$253) per year of life saved and adding a catch-up vaccination was R \$804 (US\$503) per year of life saved. When the benefits of preventing HPV16/18-related cervical diseases were considered alone, the ICER for routine vaccination was R\$717 (US \$448) per QALY and adding a catch-up vaccination was R\$1117 (US\$698) per QALY. When the assumed duration of vaccine protection was reduced from lifelong to 20 years, the ICER for routine and a catch-up vaccination strategy was R\$1049 (US\$656) per QALY gained compared to no vaccination. Cost of vaccines and discounting rate also influenced the results. Finally, when we examined the pessimistic scenario, we found that ICER comparing routine and a catch-up vaccination versus no vaccination was R\$1596 (US\$998) per QALY gained.

\section{Discussion}

Our study demonstrates that quadrivalent HPV female vaccination can substantially reduce the burden of cervical diseases and genital warts in Brazil. The major advantage of our analytic approach is the use of transmission dynamic model that incorporates the direct and indirect benefits of vaccination while evaluating effectiveness at the population level over time. We found that the routine vaccination of 12-year-old girls in combination with a catch-up vaccination of 12 to 26-year-old women can be a cost-effective strategy that can achieve earlier and greater reduction in HPV-related diseases than the routine vaccination. Routine vaccination in combination with a catch-up vaccination could prevent approximately 163,000 cases of cervical cancer, 48,000 deaths from cervical cancer, 2.3 million cases of CIN2/3, and 11.4 million genital warts in the next 50 years.

The World Health Organization considers an intervention to be "very cost-effective" when its incremental cost-effectiveness ratio is below GDP per capita [31]. We found that the incremental cost-effectiveness ratios for 

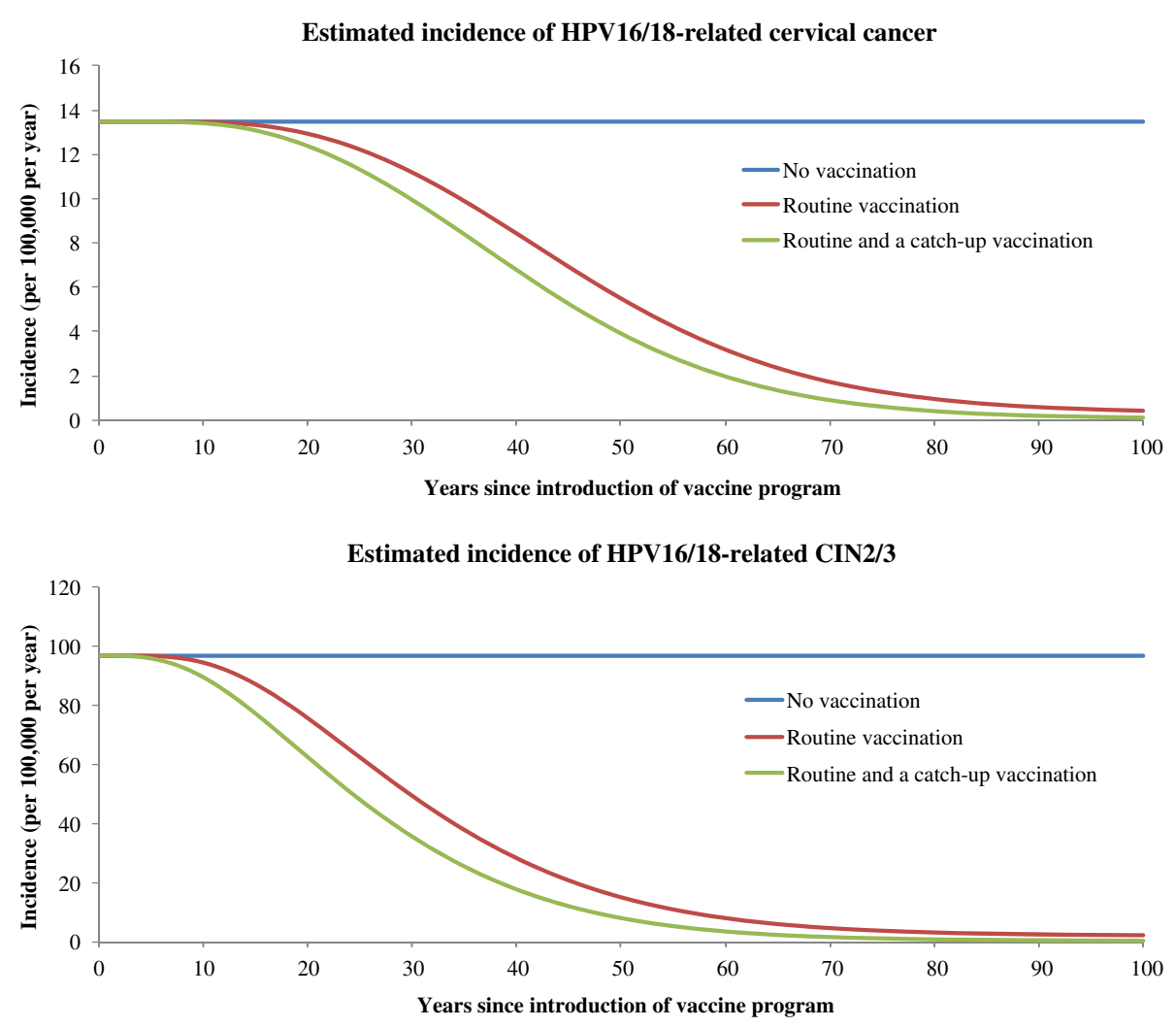

Estimated incidence of HPV6/11-related genital warts among females
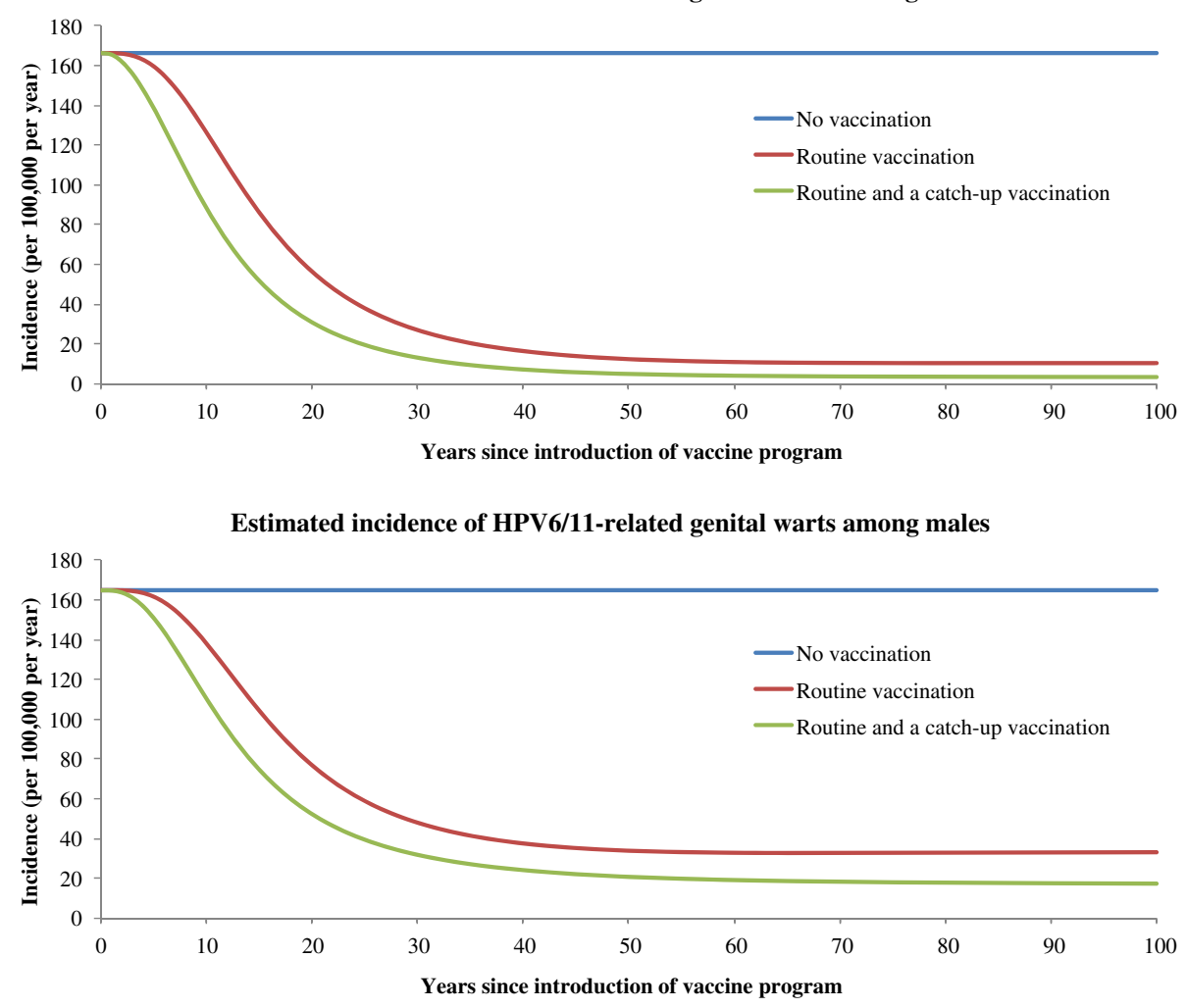

Figure 1 (See legend on next page.) 
(See figure on previous page.)

Figure 1 The incidence rates of HPV16/18-related cervical cancer, HPV16/18-related CIN2/3, and HPV6/11-related genital warts among females and males by vaccination strategy during the next $\mathbf{1 0 0}$ years. We assumed that approximately $71 \%$ of cervical cancer cases were attributable to HPV 16 and 18, and 90\% of genital warts cases were attributable to HPV 6 and 11 in Brazil.

HPV vaccination strategies ranged from US\$219 to US $\$ 450$ per QALY gained, which fell below a GDP per capita (US\$10,710 in Brazil). In order to address uncertainty of the parameters, we conducted extensive one-way sensitivity analyses. For an example, duration of protection remains uncertain. Even when we decreased the duration of vaccine protection to 20 years, we found that the HPV vaccination was cost-effective especially the vaccination strategy that included a catch-up vaccination. Four prior studies examined the cost-effectiveness of HPV vaccination in Brazil [7-10]. Goldie et al. (2007) used individual-based stochastic models and showed that routine vaccination would cost I\$120 to I $\$ 820$ per year of life saved [7]. Kim et al. (2007) also found vaccination to be cost-effective using dynamic models [8]. Using the similar individual-based dynamic model by Kim et al., Vanni et al. (2012) recently found that the ICER for the quadrivalent HPV vaccination that incorporated the benefits of preventing genital warts to be US\$255/QALY assuming similar cost of vaccination as ours ( $\$ 55$ for a total cost of vaccinating woman) with discounting at $5 \%$ [10]. Colantonio et al. (2009) used Markov models and found the ICER to be US\$10,200 per QALY assuming US\$210 for a total cost for vaccinating woman [9]. Higher ICER results may be because Colantonio et al. (2009) assumed higher vaccine cost than ours and used cohort model that did not take into account of herd immunity. In spite of differences in the model structure and assumptions about model parameters regarding natural history of HPV disease, vaccine property, health utilities, and costs, all studies consistently found HPV vaccination of females to be cost-effective in Brazil.

Contrary to most previous studies, we incorporated the potential impact of vaccination on HPV6/11-related genital warts. The quadrivalent HPV vaccine was projected to reduce the incidence of genital warts in a short period of time. This is consistent with a rapid decline in the incidence of genital warts observed among young women in Australia where vaccination has been already implemented [32,33]. Although numerous studies from North America and Europe have shown that HPV female vaccination is generally cost-effective, our incremental cost-effectiveness ratios in Brazil were lower than that in those countries [34-36]. Despite the low cost of treatment for HPV-related diseases, quadrivalent HPV vaccination in Brazil can be a cost-effective intervention, because it can prevent substantial burden of cervical cancer and genital warts.

Our model projected that HPV vaccination could prevent approximately 163,000 cases of cervical cancer, 48,000 deaths from cervical cancer and 11.4 million genital warts in the next 50 years. Many women who suffer from cervical cancer are young and actively caring for their families and it could have devastating consequences to their children and families who lose their mothers. Because we cannot incorporate such effects in costeffectiveness analysis, our results likely underestimate the potential societal benefits of vaccination. Moreover, our model projected the substantial impact of HPV vaccination on genital warts, which may have long-term psychological and/or physical consequences and profoundly affect patient's quality of life [29,37]. For example, even after treatment, women and men may experience anxiety of recurrence or persistence of genital warts [29]. Reducing cases of genital warts will not only reduce healthcare utilization but will also free up resources for diagnosis and treatment of other diseases.

Our study has several limitations. Although the model was built on available current knowledge on HPV diseases, more studies are needed to understand the

Table 3 Estimated cumulative cases of HPV-types 6/11/16/18-related disease prevented with routine vaccination of 12 year-old girls or routine vaccination combined with a catch-up vaccination of 12- to 26-year-old women in Brazil

\begin{tabular}{|c|c|c|c|c|c|c|c|c|}
\hline \multirow[t]{2}{*}{ HPV-related diseases } & \multicolumn{4}{|c|}{ Routine vaccination } & \multicolumn{4}{|c|}{ Routine and a catch-up vaccination } \\
\hline & 10 years & 25 years & 50 years & 100 years & 10 years & 25 years & 50 years & 100 years \\
\hline Cervical cancer & 22 & 6,449 & 118,825 & 712,067 & 117 & 12,954 & 162,769 & 795,693 \\
\hline Cervical cancer deaths & 3 & 1,296 & 33,698 & 247,572 & 15 & 2,700 & 47,802 & 278,283 \\
\hline CIN1 & 3,797 & 132,541 & 763,332 & $2,437,178$ & 14,744 & 218,133 & 943,965 & $2,674,632$ \\
\hline $\mathrm{CIN} 2 / 3$ & 4,412 & 250,896 & $1,829,778$ & $6,498,426$ & 18,948 & 435,052 & $2,301,481$ & $7,135,912$ \\
\hline Genital warts among women & 117,260 & $1,523,777$ & $5,235,130$ & $13,151,591$ & 318,735 & $2,180,661$ & $6,177,401$ & $14,459,056$ \\
\hline Genital warts among men & 70,649 & $1,173,031$ & $4,314,599$ & $11,031,658$ & 189,698 & $1,691,626$ & $5,199,269$ & $12,650,796$ \\
\hline
\end{tabular}


Table 4 Cost-effectiveness analysis of HPV types 6/11/16/18 vaccination in Brazil

\begin{tabular}{|c|c|c|c|c|c|c|}
\hline \multirow[t]{2}{*}{ Strategies $^{1}$} & \multicolumn{3}{|c|}{ Discounted total } & \multicolumn{3}{|c|}{ Incremental } \\
\hline & Costs (R\$) /person & QALYs /person & Costs (R\$) /person & QALYs /person & Costs (R\$) /QALYs & Costs (US\$) /QALYs \\
\hline No vaccination & 90.64 & 27.03841 & - & - & - & - \\
\hline Routine vaccination & 94.38 & 27.04912 & 3.74 & 0.01071 & 350 & 219 \\
\hline $\begin{array}{l}\text { Routine and a catch-up } \\
\text { vaccination }\end{array}$ & 96.09 & 27.05150 & 1.71 & 0.00238 & 720 & 450 \\
\hline
\end{tabular}

${ }^{1}$ Strategies are listed in order of increasing effectiveness.

natural history of HPV. Detailed data specific to Brazil, such as healthcare seeking behaviors and age- and stagespecific mortality rates from cervical cancer, were limited. Because health utility data were not available from Brazil, we used the health utility values from the U.S. Our model does not incorporate demographic changes in the future, such as population growth. Our model did not account for any temporal changes in screening practice or possible introduction of new screening methods such as HPV DNA testing. As some researchers have examined, it is important to consider screening changes in future research $[38,39]$. Although the coverage rate of HPV vaccination is unknown, we

Table 5 Incremental cost-effectiveness ratio (ICER) for sensitivity analyses

\begin{tabular}{|c|c|c|}
\hline \multirow[t]{2}{*}{ Parameter } & \multirow{2}{*}{$\begin{array}{c}\begin{array}{c}\text { Routine } \\
\text { vaccination }\end{array} \\
\text { US\$ per QALYs }\end{array}$} & \multirow{2}{*}{$\begin{array}{c}\text { Routine and } \\
\text { a catch-up } \\
\text { vaccination } \\
\text { US\$ per QALYS }\end{array}$} \\
\hline & & \\
\hline Base case & 219 & 450 \\
\hline $\begin{array}{l}\text { Cost per year of life saved } \\
\text { (no quality of life adjustments) }\end{array}$ & 253 & 503 \\
\hline $\begin{array}{l}\text { HPV16/18-related cervical } \\
\text { diseases only }\end{array}$ & 448 & 698 \\
\hline $\begin{array}{l}\text { Duration of vaccine } \\
\text { protection }=20 \text { years }\end{array}$ & Dominated ${ }^{1}$ & 656 \\
\hline $\begin{array}{l}\text { Vaccine coverage }=50 \% \text { for } \\
\text { routine and } 60 \% \text { for catch-up }\end{array}$ & 106 & 250 \\
\hline $\begin{array}{l}\text { Vaccine coverage }=95 \% \text { for } \\
\text { routine and } 98 \% \text { for catch-up }\end{array}$ & 258 & 425 \\
\hline $\begin{array}{l}\text { High cost of vaccine series } \\
\text { (increased by } 25 \% \text { ) }\end{array}$ & 406 & 686 \\
\hline $\begin{array}{l}\text { High cost of treating HPV-related } \\
\text { disease (increased by 25\%) }\end{array}$ & 86 & 326 \\
\hline $\begin{array}{l}\text { Low cost of treating HPV-related } \\
\text { disease (decreased by } 25 \% \text { ) }\end{array}$ & 350 & 573 \\
\hline Discounted at $0 \%$ & Cost saving & Cost saving \\
\hline Discounted at 5\% & 900 & 1201 \\
\hline Pessimistic scenario ${ }^{2}$ & Dominated ${ }^{1}$ & 998 \\
\hline
\end{tabular}

"A strategy is "weakly" dominated if a more effective strategy has a lower incremental cost-effectiveness ratio.

${ }^{2}$ Pessimistic scenario assumes low HPV-related disease cost (decreased by $25 \%), 20$ years of vaccine protection, and high health utilities ( 0.97 for HPVrelated disease). assumed high coverage because Brazil has a strong national immunization program that has achieved high (>90\%) immunization coverage in many currently scheduled vaccines [40].

We only assessed fit of the adapted model by assessing overall incidence of cervical cancer and did not assess agespecific data. We did not employ calibration method that identifies parameters that best predict observed data. Moreover, because of the complexity of the model, it was not feasible to conduct probabilistic sensitivity analysis.

Our projected incidence rates of HPV6/11-related genital warts were comparable to the previously reported incidence rates in other parts of the world [28-30]. A survey conducted by the Ministry of Health in Brazil found that $5.7 \%$ of pregnant women reported having a history of clinical diagnosis of genital warts [25]. However, data regarding the incidence of genital warts in the general population in Brazil were not available.

HPV vaccine may have cross-protection against nonvaccine, oncogenic HPV-types; however, the duration and efficacy of the cross-protection remains uncertain [41]. If this additional benefit of vaccine was considered, we would have more favorable cost-effectiveness. We did not consider the potential benefits of HPV vaccination on other HPV-related diseases such as vulvar, vaginal, anal, head and neck, and penile cancers, and recurrent respiratory papillomatoses. Previous studies in the U.S. included these diseases and showed an improvement in incremental cost-effectiveness ratios $[12,42]$. The HPV vaccination of males could also be important because it may prevent some of these cancers and genital warts.

\section{Conclusion}

In conclusion, our study demonstrates that quadrivalent HPV vaccination can substantially reduce the burden of cervical diseases and genital warts in Brazil. Our model results show that HPV vaccination of females, particularly routine vaccination of 12-year-old girls in combination of a catch-up vaccination of 12 to 26-year-old women, can be a cost-effective intervention in Brazil.

\section{Competing interests}

This study was supported by Merck \& Co., Inc. KK is a post-doctoral fellow funded by Merck \& Co., Inc. MP is a consultant working with Merck \& Co., Inc. PKS is employed by Merck \& Co., Inc. 


\section{Authors' contributions}

KK, GTBA, and MF collected data. KK, MP, and PKS performed the analyses KK drafted the manuscript. All authors reviewed and approved the final version of the manuscript.

\section{Acknowledgements}

We thank Erik J. Dasbach and Thomas Weiss (Merck \& Co., Inc.) for their helpful comments on the manuscript.

\section{Author details}

${ }^{1}$ Temple University, 3307 N. Broad Street, Philadelphia, PA, 19140, USA. ${ }^{2}$ Axia. Bio, São Paulo, Brazil. ${ }^{3}$ Federal University of São Paulo - UNIFESP, São Paulo, Brazil. ${ }^{4}$ Atlas Data Systems, Westfield, NJ 07090, USA. ${ }^{5}$ Merck \& Co., Inc., West Point, PA 19486, USA.

Received: 5 December 2011 Accepted: 1 October 2012 Published: 9 October 2012

\section{References}

1. Arbyn M, Castellsague X, de Sanjose S, Bruni L, Saraiya M, Bray F, Ferlay J. Worldwide burden of cervical cancer in 2008. Ann Oncol 2011, 22(12):2675-2686.

2. Munoz N, Castellsague X, de Gonzalez AB, Gissmann L: Chapter 1: HPV in the etiology of human cancer. Vaccine 2006, 24(3):3/1-10.

3. Villa LL, Costa RL, Petta CA, Andrade RP, Ault KA, Giuliano AR, Wheeler CM, Koutsky LA, Malm C, Lehtinen M, et al: Prophylactic quadrivalent human papillomavirus (types $6,11,16$, and 18) L1 virus-like particle vaccine in young women: a randomised double-blind placebo-controlled multicentre phase II efficacy trial. Lancet Oncol 2005, 6(5):271-278.

4. Dillner J, Kjaer SK, Wheeler CM, Sigurdsson K, Iversen OE, Hernandez-Avila M, Perez G, Brown DR, Koutsky LA, Tay EH, et al: Four year efficacy of prophylactic human papillomavirus quadrivalent vaccine against low grade cervical, vulvar, and vaginal intraepithelial neoplasia and anogenital warts: randomised controlled trial. BMJ 2010, 341:C3493.

5. Perez G, Lazcano-Ponce E, Hernandez-Avila M, Garcia PJ, Munoz N, Villa LL, Bryan J, Taddeo FJ, Lu S, Esser MT, et al: Safety, immunogenicity, and efficacy of quadrivalent human papillomavirus (types $6,11,16,18$ ) L1 virus-like-particle vaccine in Latin American women. Int J Cancer 2008, 122(6):1311-1318.

6. Brazilian National Cancer Institute (Instituto Nacional De Cancer). Available at http://www2.inca.gov.br.

7. Goldie SJ, Kim JJ, Kobus K, Goldhaber-Fiebert JD, Salomon J, O'Shea MK, Xavier Bosch F, de Sanjose S, Franco EL: Cost-effectiveness of HPV 16, 18 vaccination in Brazil. Vaccine 2007, 25(33):6257-6270.

8. Kim JJ, Andres-Beck B, Goldie SJ: The value of including boys in an HPV vaccination programme: a cost-effectiveness analysis in a low-resource setting. Br J Cancer 2007, 97(9):1322-1328.

9. Colantonio L, Gomez JA, Demarteau N, Standaert B, Pichon-Riviere A, Augustovski $F$ : Cost-effectiveness analysis of a cervical cancer vaccine in five Latin American countries. Vaccine 2009, 27(40):5519-5529.

10. Vanni T, Mendes Luz P, Foss A, Mesa-Frias M, Legood R: Economic modelling assessment of the HPV quadrivalent vaccine in Brazil: a dynamic individual-based approach. Vaccine 2012, 30(32):4866-4871.

11. Jit M, Demarteau N, Elbasha E, Ginsberg G, Kim J, Praditsitthikorn N, Sinanovic $E$, Hutubessy R: Human papillomavirus vaccine introduction in low-income and middle-income countries: guidance on the use of cost-effectiveness models. BMC Med 2011, 9:54.

12. Elbasha EH, Dasbach EJ: Impact of vaccinating boys and men against HPV in the United States. Vaccine 2010, 28(42):6858-6867.

13. Elbasha EH, Dasbach EJ, Insinga RP: Model for assessing human papillomavirus vaccination strategies. Emerg Infect Dis 2007, 13(1):28-41.

14. Insinga RP, Dasbach EJ, Elbasha EH: Epidemiologic natural history and clinical management of Human Papillomavirus (HPV) Disease: a critical and systematic review of the literature in the development of an HPV dynamic transmission model. BMC Infect Dis 2009, 9:119.

15. United Nations Department of Economic and Social Affairs Population Division: World Population Prospects: The 2010 Revision, UN.; 2011. Available in http://esa.un.org/unpd/wpp/Excel-Data/population.htm.

16. World Health Statistics: Health statistics and health information systems. World Health Organization.; 2011. Available in http://www.who.int/ healthinfo/statistics/mortality_life_tables/en/index.html.
17. Barbosa RM, Koyama MA: Sexual behavior and practices among men and women, Brazil 1998 and 2005. Rev Saude Publica 2008, 42(1):21-33.

18. de Quadros CA, Victora CG, da Costa JS: Coverage and focus of a cervical cancer prevention program in southern Brazil. Rev Panam Salud Publica 2004, 16(4):223-232.

19. Albuquerque KM, Frias PG, Andrade CL, Aquino EM, Menezes G, Szwarcwald $\mathrm{CL}$ : Pap smear coverage and factors associated with non-participation in cervical cancer screening: an analysis of the Cervical Cancer Prevention Program in Pernambuco State, Brazil. Cad Saude Publica 2009, 25(2):301-309.

20. Murillo R, Almonte M, Pereira A, Ferrer E, Gamboa OA, Jeronimo J, LazcanoPonce E: Cervical cancer screening programs in Latin America and the Caribbean. Vaccine 2008, 26(Suppl 11):L37-L48.

21. Flores-Luna L, Salazar-Martinez E, Escudero-De los Rios P, Gonzalez-Lira G, Zamora-Munoz S, Lazcano-Ponce E: Prognostic factors related to cervical cancer survival in Mexican women. Int J Gynaecol Obstet 2001, 75(1):33-42.

22. Brazil Ministry of Health: Sistema de Gerenciamento da Tabela de Procedimentos, Medicamentos e OPM do SUS (SIGTAP). Available in http://sigtap.datasus.gov.br/tabela-unificada/app/sec/inicio.jsp.

23. Azevedo E Silva G, Girianelli VR, Gamarra CJ, Bustamante-Teixeira MT: Cervical cancer mortality trends in Brazil, 1981-2006. Cad Saude Publica 2010, 26(12):2399-2407.

24. WHO/ICO Information Centre on HPV and Cervical Cancer: HPV and cervical cancer in the 2007 report. Vaccine 2007, 25(3):1-230

25. Brazil Ministry of Health: Ministério da Saúde: Programa Nacional de DST e Aids. Prevalências e frequências relativas de Doenças Sexualmente Transmissiveis (DST) em populaçōes selecionadas de seis capitais brasileiras. Brasília: Ministério da Saúde; 2008. Available in http://bvsms.saude.gov.br/php/index.php.

26. Parkin DM, Almonte M, Bruni L, Clifford G, Curado MP, Pineros M: Burden and trends of type-specific human papillomavirus infections and related diseases in the latin america and Caribbean region. Vaccine 2008, 26(Suppl 11):L1-L15.

27. d'Ottaviano-Morelli MG, Zeferino L, Cecatti JG, Terrabuio DR, Martinez EZ: Prevalence of cervical intraepithelial neoplasia and invasive carcinoma based on cytological screening in the region of Campinas, Sao Paulo, Brazil. Cad Saude Publica 2004, 20(1):153-159.

28. Insinga RP, Dasbach EJ, Myers ER: The health and economic burden of genital warts in a set of private health plans in the United States. Clin Infect Dis 2003, 36(11):1397-1403.

29. Scarbrough Lefebvre CD, Van Kriekinge G, Goncalves MA, de Sanjose S: Appraisal of the burden of genital warts from a healthcare and individual patient perspective. Public Health 2011, 125(7):464-475.

30. Desai S, Wetten S, Woodhall SC, Peters L, Hughes G, Soldan K: Genital warts and cost of care in England. Sex Transm Infect 2011, 87(6):464-468.

31. Macroeconomics and health: investing in health for economic development Report of the Commission on Macroeconomics and Health. Geneva: World Health Organization; 2001.

32. Read TR, Hocking JS, Chen MY, Donovan B, Bradshaw CS, Fairley CK: The near disappearance of genital warts in young women 4 years after commencing a national human papillomavirus (HPV) vaccination programme. Sex Transm Infect 2011, 87(7):544-547.

33. Donovan B, Franklin N, Guy R, Grulich AE, Regan DG, Ali H, Wand H, Fairley CK: Quadrivalent human papillomavirus vaccination and trends in genital warts in Australia: analysis of national sentinel surveillance data. Lancet Infect Dis 2011, 11(1):39-44.

34. Dasbach EJ, Elbasha EH, Insinga RP: Mathematical models for predicting the epidemiologic and economic impact of vaccination against human papillomavirus infection and disease. Epidemiol Rev 2006, 28:88-100.

35. Brisson M, Van de Velde N, Boily MC: Economic evaluation of human papillomavirus vaccination in developed countries. Public Health Genomics 2009, 12(5-6):343-351.

36. Koleva D, De Compadri P, Padula A, Garattini L: Economic evaluation of human papilloma virus vaccination in the European Union: a critical review. Intern Emerg Med 2011, 6(2):163-174.

37. Mortensen GL, Larsen HK: The quality of life of patients with genital warts: a qualitative study. BMC Public Health 2010, 10:113.

38. Vanni T, Legood R, Franco EL, Villa LL, Luz PM, Schwartsmann G: Economic evaluation of strategies for managing women with equivocal cytological results in Brazil. Int J Cancer 2011, 129(3):671-679. 
39. Tully SP, Anonychuk AM, Sanchez DM, Galvani AP, Bauch CT: Time for change? An economic evaluation of integrated cervical screening and HPV immunization programs in Canada. Vaccine 2012, 30(2):425-435

40. Vaccine-preventable diseases: monitoring system - 2010 global summary. World Health Organization:; 2010. Available at http://www.who.int/ immunization monitoring/data/en/.

41. Malagón TDM, Boily M, Franco EL, Jit M, Brisson J, Brisson M: Crossprotective efficacy of two human papillomavirus vaccines: a systematic review and meta-analysis. Lancet Infect Dis 2012, 12(10):781-789.

42. Chesson HW, Ekwueme DU, Saraiya M, Dunne EF, Markowitz LE:

The cost-effectiveness of male HPV vaccination in the United States. Vaccine 2011, 29(46):8443-8450.

doi:10.1186/1471-2334-12-250

Cite this article as: Kawai et al:: Estimated health and economic impact of quadrivalent HPV (types 6/11/16/18) vaccination in Brazil using a transmission dynamic model. BMC Infectious Diseases 2012 12:250.

\section{Submit your next manuscript to BioMed Central and take full advantage of:}

- Convenient online submission

- Thorough peer review

- No space constraints or color figure charges

- Immediate publication on acceptance

- Inclusion in PubMed, CAS, Scopus and Google Scholar

- Research which is freely available for redistribution 